\title{
Evaluating Access, Quality, and Equity in Online Learning: A Case Study of a MOOC- Based Blended Professional Degree Program
}

\author{
Joshua Littenberg-Tobias, Massachussets Insitute of Technology \\ Justin Reich, Massachussets Insitute of Technology
}

\begin{abstract}
As massive open online courses (MOOCs) shift toward professional degree and certificate programs, can they become a global on-ramp for increasing access to emerging fields for underrepresented groups? This mixed-methods study addresses this question by examining one of the first MOOC-based blended professional degree programs, which admitted students to an accelerated residential master's program on the basis of performance in MOOCs and a proctored exam. We found that male students and students with master's degrees were more likely to complete the online program and the blended program had more male students and more students with master's degrees than students in the existing residential program. Students who enrolled in the blended graduate program earned higher average grades than students in the residential program earned in their in-person courses (3.86 vs $3.75, p<0.01$ ). The findings of this study provide an example of how new online learning models can serve particular niches, but may not address broader equity challenges.
\end{abstract}

Keywords: online learning, professional education, MOOCs, access, admissions 


\section{Evaluating Access, Quality, and Equity in Online Learning: A Case Study of a MOOC- Based Blended Professional Degree Program}

\section{Introduction}

Massive open online courses (MOOCs) have become a high-profile feature of the online educational landscape, offering free online courses that attract millions of learners (DeBoer et al., 2014; Perna et al., 2014). At the onset of MOOCs, some scholars lauded MOOCs as one potential solution to the global demand for higher education (Alcorn et al., 2015). MOOC advocates originally described their efforts as a way to expand educational opportunities by offering free, online classes from elite U.S. institutions such as Stanford, MIT, and Harvard at a large scale (Perna et al., 2014). In the past few years, however, major MOOC providers have transitioned from offering freely accessible courses to some type of paywall system that limits all or parts of course to those who pay a fee (Shaw, 2019). Though a few voices continue to promise disruptive change in higher education through online learning (Christensen, 2017), there is a growing consensus that MOOCs will be integrated into existing higher education systems rather than upending the systems entirely (Al-Imarah \& Shields, 2018; Reich \& Ruipérez-Valiente, 2019).

One way MOOC providers have adapted to this changing landscape is by working with higher education institutions to create new professional credentials and graduate degree programs, including both fully online and blended online/in-person programs. These new online and blended programs are targeted at early and mid-career professionals who are seeking jobrelated skills and credentials. Proponents claim that these programs have the potential to serve a global market of professionals looking for flexible, lower-cost, alternatives to traditional professional degree programs (Caudill, 2017; Joyner, 2018; Zheng et al., 2018). 
In this study, we examine the experiences of students in one of the first blended MOOCbased degree programs, a professional master's program in supply chain management offered by the Center for Transportation and Logistics at the Massachusetts Institute of Technology (MIT). ${ }^{1}$ Supply chain management is a rapidly growing field of study concerning logistics and operations within increasingly global supply chains (McCrea, 2016). The program consisted of two components. MIT offered a non-degree credential in supply chain management, called a MicroMasters, through MOOCs. To earn a MicroMasters, students needed to pay for and complete five MOOCs and pass a proctored exam. Students who earned the MicroMasters were then eligible to apply for a semester-long accelerated version of a residential master's degree program on campus at MIT or with a partner institution that agreed to recognize the MicroMasters credential and offer a similar accelerated residential master's program. Students in the accelerated master's degree did not have to submit standardized test scores or undergraduate grades as was required for admission to the year-long residential master's degree in supply chain management. In effect, the MicroMasters represented an "inverted admissions” track, where admission into the accelerated residential master's degree program was contingent on performance in the open admissions MicroMasters program.

Through studying this program, we explore a question that has recently come to prominence in the online higher education literature: to what extent do new online learning models, like MOOC-based degree or credential programs, broaden access to new, underserved, populations (Goodman et al., 2016) or how might they exacerbate inequality by increasing the opportunities of those who are most capable of taking advantage of new technologies(Hansen \& Reich, 2015)? 
We explore these questions through the lenses of access, equity, and quality. Higher education researchers describe access as having an equal opportunity to participate in higher education (Clancy \& Goastellec, 2007). MOOCs are often described as promoting access to higher education by providing entry points into higher education with lower stakes and costs than traditional higher education offering (Koller et al., 2013; Perna et al., 2014). However, in practice, access to equal opportunities does not ensure equal outcomes because of structural inequalities that privilege the already advantaged (Peurach et al., 2019; Roemer \& Trannoy, 2015). An equity perspective argues that access to equal opportunities is not sufficient and that compensatory measures are needed in order to ensure that all groups can have equal outcomes (Clancy \& Goastellec, 2007; Lim et al., 2018). Finally, quality in a professional setting is the extent to which the learning experiences develop the knowledge and skills to be successful within a professional field. As Jones (2013) observes, quality professional learning allows student to gain a "well-developed, comprehensive and readily recalled domain knowledge, the capacity to scrutinise both the well-articulated and tacitly held basis for their decision making and action and an attitude of systematic enquiry and knowledge building to improve their theory of practice.” (p.58). For working professionals, flexibility is a key component of quality learning experiences. Professionals working full-time jobs did need learning opportunities that can effectively be completed outside the traditional work day (Donavant, 2009).

Although MOOCs have the potential to provide asynchronous quality professional learning experience due to their flexibility some researchers have raised concerns about the lowinstructional quality of some MOOCs. Many MOOCs provide few opportunities for working on authentic, ill-structured problems or provide opportunities for learners to apply their knowledge to solve problems (Margaryan, Bianco, \& Littlejohn, 2015). From an equity perspective, it is a 
problem if MOOC-based degree programs increase access but have low instructional quality because it means the students who most need high-quality instruction, those without prior educational advantages, would be least likely to receive it.

The blended MOOC-based degree in supply chain management is a compelling case study to examine these issues because the field suffers from a lack of gender, educational, and racial diversity in supply chain management positions (Burgess et al., 2017; Nix \& Stiffler, 2016) and increasing access to supply chain management education was part of the original goals of the program (Mingle, 2018). For these programs to advance equity, they must not only increase access to instructional materials but they should provide quality professional learning experiences and compensatory supports that enable those from under-represented groups to advance in their professional field. As one of the first examples of MOOC-based blended professional degree programs, it allows us to examine the emergence of a new online learning innovation, professional MOOC-based degree and credential programs, and explore how MOOC-based programs conduct admissions, prepares learners, and ultimately credential students. Additionally, the

\section{Background}

\subsection{MOOCs and the debate over quality, access, and equity in online higher education}

The field of online higher education has grown rapidly in the last decade. In 2013, 27\% of undergraduate, degree-seeking students in the U.S. were enrolled in one course online and $11 \%$ were enrolled in fully online programs (Deming et al., 2015). By 2017, only four years later, those numbers had increased to 33\% taking at least one course online and $18 \%$ enrolled in fully online programs (Lederman, 2018). Demand for higher education, particularly in the Global South, has led to a massive rise in online higher education (Alcorn et al., 2015). 
For many years, universities outsourced creating new online programs to for-profit Online Program Managers (OPMs) who are put in charge of marketing, online infrastructure, instructional design and even instruction and assessment (Mattes, 2017). OPMs usually invest the capital to create the courses upfront in exchange for an ongoing share of tuition revenue (McKenzie, 2018). OPMs are now a multi-billion dollar industry with large for-profit education companies such as Pearson, Wiley, and 2U offering these services to universities (Hill, 2018).

With the shift toward creating more fully-online and blended degree programs for professionals, MOOC providers such Udacity, Coursera, and edX are now competing directly with these established OPMs that work with executive education and online degree programs (Young, 2018). This "MOOCs as OPMs" model offers some hypothesized benefits to higher education institutions with respect to access and equity. By offering blended and online-only degrees through MOOCs, MOOC providers argue that higher education institutions can expand the pool of potential students - serving a more globally and socio-economically diverse audience and meeting global needs for skilled workers (edX, 2018).

Within MOOC-based degrees, new technologies also promise to reduce tuition costs by automating faculty labor through recorded lectures and auto-graded assessments, while maintaining quality by drawing content from elite institutions. These reduced costs might then make these online and blended forms of higher education more affordable and thus more accessible to diverse, global populations. Degrees and credentials offered by MOOC providers has the potential to decelerate the rapid rise in higher education costs, thereby making higher education more accessible. In 2014, Georgia Tech and Udacity offered the first MOOC-based online master's degree in Computer Science, which was designed to emulate the in-person program at one-sixth of the cost (Goodman et al., 2016). Goodman et al. (2016) found causal 
evidence that the program increased enrollment among older students who otherwise would have been unlikely to enroll in a computer science master's degree program, and students in the online offering had bachelor's degrees from schools serving greater proportions of low-income students than students in the equivalent residential program.

However, revenue-seeking and expanding opportunity can be misaligned incentives for institutions considering online courses. Research on existing OPMs has found that external providers are incentivized to prioritize revenue and enrollment maximization over instructional quality and student support (Mattes, 2017; Russell, 2010). To the extent that MOOC providers decide to pivot towards serving as OPMs, they will likely face similar pressures to prioritize enrollment over instructional quality and equitable access.

The initial research on MOOCs offers cautionary notes about both instructional quality and equity. MOOCs have been criticized for weak pedagogical practices and student supports (Margaryan et al., 2015; Milligan \& Littlejohn, 2016). In particular, researchers have emphasized the importance of self-regulated learning strategies, such as a such as goal-setting, strategic planning, and monitoring (Zimmerman, 1989), in being successful in the less-supported learning environments of MOOCs (Kizilcec et al., 2017; Littlejohn et al., 2016). Researchers have found these self-regulated learning behaviors are also correlated with learners' educational attainment (Kizilcec et al., 2017) and professional identity (Littlejohn et al., 2016). As a result, online professional degree MOOCs may deepen disparities by offering access to low-cost professional learning degrees for only those with resources and well-developed self-regulated learning skills to successfully navigate a MOOC (Bartolomé \& Steffens, 2015; Milligan \& Littlejohn, 2016).

\subsection{MicroMasters: Experimenting with a stackable professional credential}


One emerging trend in the "MOOCs as OPMs model" is using MOOCs as a combined pre-enrollment admissions and credit-transfer mechanism. Students can be admitted into degree programs based on demonstrated competency in the subject area, as measured through their performance in a MOOC, rather than based on traditional measures such as standardized test scores or grade point average (GPA), which are correlated with socio-economic status (Gershenson, 2018; Sackett et al., 2012). Additionally, MOOC courses can be transferred into academic credit once the student enrolls in the university. One well-known, example of this type of program is Arizona State University's Global Freshman Academy. In this program, students can enroll in first-year undergraduate courses online through edX for a fraction of the course of a typical undergraduate course (\$200 per credit), which students only pay if they successfully complete the course (Ehrenberg, 2015). Students can then apply this course credit toward inperson credit at Arizona State or another institution - essentially bypassing the freshman admissions process and enrolling in the institution with sophomore status (Ehrenberg, 2015)

In 2015, edX and MIT experimented with a new approach to blended degree programs: a MicroMasters, a low-cost non-degree online certificate that was linked to a blended master's degree in supply chain management. The program was offered through MIT's Center for Transportation and Logistics (CTL). Founded in 1973, the CTL conducts research and consulting related to logistics and operations management, and offers master's degrees, doctoral degrees, and executive education programs. MIT faculty and staff developed the content and designed the courses. The course design set-up for asynchronous learning. Video-record lectures explained high-level concepts in supply-chain main management and related to business applications. Assessments focused on integrating the ideas and concepts from the course with authentic scenarios. Community assistants provided real-time support within the course forums. 
One of the originally stated goals of the program was to expand access to supply chain management expertise (Chandler, 2017). Although supply chain management is an increasingly global important field; the field is dominated by males in North America and Europe with business degrees (Burgess et al., 2017). For example, a 2016 survey found that females made up only $35 \%$ of the total supply chain workforce and only $7 \%$ of executive-level positions in the field (Nix \& Stiffler, 2016). Particularly, with the growing importance of fields such as sustainable supply chain management (Matthews et al., 2016) and the role of gender and racial diversity in supply chains (Chin \& Tat, 2015; Whitfield \& Farrell, 2010), increasing the percentage of individuals from underrepresented groups in supply chain management positions is increasingly recognized as an important goal for the field (McCrea, 2018) .

In statements made around the time the MicroMasters launch, MIT faculty involved with the program emphasized the benefits of the program for improving access to education. For example, in a Washington Post article when the MicroMasters program was first announced, an MIT administrator described the supply chain management MicroMasters as "democratizing access to a master's program for learners worldwide" (Anderson, 2015).

The structure of the supply chain management MicroMasters and blended program was set-up as a sequential process. Students intending to complete the MicroMasters program were required to complete five online courses on supply chain management and pass a proctored assessment. These credentials were intended to be "stackable"; students could use the supply chain management MicroMasters as a stand-alone credential or they could apply the MicroMasters toward course credit and advanced standing in the residential degree program at MIT or to other graduate degree programs that allow students to transfer credits from the MicroMasters (Young, 2018) much in the way that an associate's degree can stand alone or 
"stack" into a bachelor's degree (Brint \& Karabel, 1989). Students were admitted to the MIT graduate program largely based on their performance in the MOOCs and were not required to submit standardized test scores or undergraduate grades. The admissions process was "inverted" - that is, as anyone could sign-up to participate in the online courses, but students would first need to demonstrate proficiency in the subject area before they were officially admitted to the residential master's degree program at MIT or a partner institution.

\section{Study Rationale}

When new educational technologies emerge, they often arrive with a set of implicit assumptions about how these technologies will affect learning (Reeves et al., 2005). In this case study, we sought to categorize and evaluate these assumptions which we describe as design hypotheses, about MicroMasters and MOOC-based blended master's degree programs within the context of this program. By framing our study around these design hypotheses, we sought to better understand the potential affordances and limitations of these new technologies and their implications for expanding access to online professional education more broadly.

Design Hypothesis 1: MicroMasters and MOOC-based blended graduate degree programs can expand access to professional education by diversifying the pool of potential students. These pathways can expand access to new types of students - such as females in underrepresented fields, those with less formal education, or those from less developed countries - who otherwise would not have pursued a degree or credential through a higher education institution. By offering a lower price point, making courses accessible online, and offering an inverted admissions process for in-person learning, MOOC-based degree pathways may potentially offer opportunities to a more diverse pool of students than traditional higher education offerings. Particularly for fast-growing global fields such as supply chain 
management, these professional credential and degree programs may serve as an educational onramp for students looking to rapidly improve their employment opportunities.

\section{Design Hypothesis 2: Online learning experiences can provide quality professional}

learning at lower costs. High-quality learning for professionals provides practice-centered, jobrelevant learning that offers flexibility for working professionals (Costley, 2013; Donavant, 2009; Jones, 2013). Student should have the opportunities to learn the fundamental domain knowledge of the professional field (Jones, 2013) and have opportunities to apply that knowledge to authentic, ill-structured problems (Margaryan et al., 2015). For certain subjects, online courses can provide quality professionals learning experiences at lower tuition costs. Ideally, program designers can identify learning experiences that are better suited for online study - declarative knowledge, quantitative or computational operations, and introductory materials - and include those in low-cost, massive open online courses.

\section{Design Hypothesis 3: Inverted admissions for professional graduate degree} programs can attract high-quality students who otherwise would not attend. Through preenrollment "inverted admissions" processes, students can be admitted into professional graduate programs based on their performance in MOOCs. This has the potential to select high-quality students who would not otherwise be admitted or enroll, because students can be selected on the basis of demonstrated interest and competency in the field, instead of evaluating academic competence through grades and standardized tests which may not be as relevant for professional fields such as supply chain management. 


\section{Data and Methods}

\subsection{Study population}

In this case study, we focus on the first cohort of students who participated in the online MicroMasters in supply chain management and the subset of student who subsequently enrolled in the first accelerated blended master's program at MIT through the "inverted admissions" process. As is true with many studies of MOOC learners, attrition within courses and between courses in the program means that there are multiple populations of interest that are useful in answering different kinds of questions (Clow, 2013). From April 2015 to May 2017, when applications were due for the blended program (Figure 1):

- $\mathbf{8 1 , 0 0 0}$ students had participated in at least one of the supply chain management MOOCs

- $\mathbf{7 , 9 9 9}$ were "verified" students meaning they paid the fee for at least one course to have the opportunity to earn a certificate and for the course to count toward the MicroMasters.

- $\quad \mathbf{3 , 8 0 4}$ had earned a certificate for at least one course in the MicroMasters sequence

- $\mathbf{6 2 2}$ of them had earned a MicroMasters.

- 130 applied for the accelerated master's program at MIT

- 40 enrolled and arrived on campus in January 2018 as the inaugural blended cohort in the program

[Insert Figure 1 Here]

When the first blended cohort arrived, they joined the existing cohort of 42 residential students in a traditional full-year supply chain management master's program. Both cohorts 
completed the program in June 2018. All 82 students participated in January-term courses together and took one required course together in the spring semester. In the spring semester, students were also required to take at least three elective courses, including a capstone or thesis course.

\subsection{Mixed-methods study design}

We used an iterative, integrated, mixed-methods design, where the "mixing" of the quantitative and qualitative data occurs throughout the inquiry process; from data collection through the interpretation phase (Teddlie \& Tashakkori, 2006). Iterative integrated designs enable this process to occur over several stages, allowing what Greene and Caracelli (1997) describe as the "progressive reconfiguration of substantive findings and interpretations in a pattern of increasing insight and sophistication" (p.23). Using this approach facilitates exploration into the interplay between the qualitative and quantitative data sources, and allowed us to modify our data collection and analysis in response to new information (Greene \& Caracelli, 1997).

\subsection{Data sources and analysis}

In this study, we examined a variety of quantitative and qualitative data sources including $\log$ data from the five MOOC courses in the MicroMasters program, entrance surveys from online course participants, and end-of-semester surveys from students in the blended and residential master's degree programs. Below, we summarize the quantitative and qualitative data sources we examined in this study and the methods we used to analyze the data. Further details about the analysis are available in the technical appendix. The data collection and analysis procedures used in this study were approved by the Committee on the Use of Humans as Experimental Subjects at MIT. 


\subsubsection{Log data}

We analyzed log data from edX from all students who participated in one of the five MOOC courses in the program (with 8 total course runs) from April 2015 to May 2017 ( $\mathrm{N}=$ $81,000)$. We assessed the edX data using tables generated by the edx2bigquery open-source Python package (Lopez et al., 2017). We examined four research-based indicators of learner activity (Kizilcec et al., 2017; Littlejohn et al., 2016): the total time spent in the course, the number of times participants posted in the community forums, the number of times users revisited previously watched videos, and the number of times users revisited previously completed assessments. We analyzed differences in learner activity using a non-parametric distributional test (Wilcoxon-Mann-Whitney test) to account for the highly skewed distribution of the data.

\subsubsection{Demographic data}

edX administered a brief demographic survey when participants signed up for courses on edX.org. The survey included questions about their age, gender, and level of education. Additionally, the edX server records the modal IP address of each student when they are taking the course which allows for identification of user's country. Demographics were disaggregated by the level of completion of the program in order to identify demographic trends in program participation and completion.

\subsubsection{MOOC entrance surveys}

Every edX course from MIT, including the courses in the SCM MicroMasters sequence, administered a standardized entrance survey to participants at the beginning of the courses. The survey questionnaire asked participants about their backgrounds and motivations for participation. We matched at least one entrance survey for $29 \%$ of non-verified participants, $65 \%$ 
of verified students who did not complete any courses, $81 \%$ of students who certified for at least one course but did not complete the sequence, $96 \%$ of non-blended MicroMasters completers, and $92 \%$ of blended students.

\subsubsection{Master's program end-of-semester surveys}

We sent out an end-of-semester survey to students in both the blended $(\mathrm{N}=34 ; 85 \%$ response rate) and residential cohorts $(\mathrm{N}=34 ; 81 \%$ response rate) in the master's degree program in supply chain management in May 2018. The survey asked students about their academic experiences in their residential courses, interactions with faculty and other students, and their sense of belonging to the institution. Survey items were adapted from items from existing surveys on student experiences in higher education (Hausmann et al., 2009).

\subsubsection{Academic grades}

We received de-identified course grades for students in both the blended and residential cohorts from the university's office of institutional research. These grades included both classes offered within the degree program and electives students took outside of the program at MIT. Additionally, for purposes of comparison, we obtained the grade distributions of students not enrolled in the supply chain management program for any classes where there was at least one blended or residential student in the class. For ease of interpretation, we standardized students course grades so they were on a 0-4 point grading scale (e.g., $3.7=\mathrm{A}-, 4.0=\mathrm{A})$.

\subsubsection{In-person interviews}

We conducted semi-structured interviews at the beginning of the January 2018 term. Invitations were sent to all students in both the blended and comparable full-year residential cohort. We interviewed all students who responded to our interview request, in total, 33 blended students (83\% response rate) and 18 residential students (43\% response rate). There were no 
meaningful differences in gender, prior education, age, and geographic origin between those who participated in interviews and their pers who did not (see Table A2 in the Supplementary Materials). We also conducted follow-up interviews at the end of the semester with a random sample of blended students that we interviewed during the first round $(\mathrm{N}=9,60 \%$ response rate).

\subsubsection{Interview coding and analysis}

We approached qualitative coding of the data using a grounded theory approach; where there are no pre-existing assumptions about the structure or themes in the data (Glaser \& Strauss, 1967). We chose this approach because MOOC-based online and blended pathways are relatively new and we wanted to have the flexibility to pursue new ideas and concepts that emerge within the data without being constrained by pre-existing models that might not fit the data (Heath \& Cowley, 2004).

We began the process of coding the interviews by open coding a sample of interviews $(\mathrm{N}$ =8) using a constant comparative approach (Boeije et al., 2002; Glaser \& Strauss, 1967). Each interview was coded independently by three raters (one author and two undergraduate research assistants) to identify emergent themes in the data. We then collapsed these codes into a set of 11 thematic codes that we consistently identified across different interviewees. Once we decided on the thematic codes, we conducted a norming exercise to ensure that all coders had a consistent understanding of how to apply the codes and only began coding once we had achieved a sufficient level of inter-rater reliability.

In total, raters coded 1,262 excerpts from 49 interviews with $41 \%$ of interviews coded by at least two independent raters. We then calculated the pooled kappa which is a version of Cohen's kappa that can be applied in situations where there are multiple codes that could 
potentially be applied to the same line of text (De Vries et al., 2008). The overall pooled kappa from all of the interviews was 0.72 and no combination of raters had a pooled kappa lower than 0.67. The distribution of codes from the interviews can be found in the supplementary materials (Table A1). In our writing, we integrated illustrative examples of select thematic codes, highlighting representative examples where the qualitative and quantitative findings intersect.

\section{Findings}

\subsection{Design Hypothesis 1: MicroMasters and MOOC-based blended graduate degree} programs can expand access to higher education by diversifying the pool of potential applicants

The supply chain management MicroMasters program attracted a population of learners very similar to those found in other STEM MOOCs and MOOCs from technical professions. In Table 1, we show the age, gender, country of origin, and level of education of participants in the online courses, organized by their progress through the online courses, as well as the 2017-2018 full-year residential cohort of the SCM master's degree. Like many STEM MOOCs, typical participants were mid-career, male, from an OECD country (an indicator of economic development), and many already had a master's degrees (Ho et al., 2015).

However, even among this initially imbalanced population of participants, there were increasingly higher proportions of male students and students with master's degrees as learners progressed through the program (Table 1). For example, among participants who paid the verification fee for at least one course but did not complete any courses, $25 \%$ were female, and $35 \%$ had a master's degree. By comparison, among learners who completed the MicroMasters (but did not enroll in the blended program) 12\% were female and 51\% had master's degrees. 
The MicroMasters cohort was also less diverse in several important dimensions than the cohort that enrolled in the traditional residential program. In the residential cohort, $40 \%$ of students were female and 19\% had master's degrees. The MicroMasters cohort was also more likely to be from an OECD country than those in the residential cohort (68\% compared to 45\%). The cohort of students who enrolled in the blended program was more gender-balanced than the MicroMasters cohort but still disproportionately male (only $28 \%$ of participants were female) and had a high number of students with master's degrees (57\%).

However, there were students who completed the MicroMasters who did not fit the profile of students who traditionally enrolled in the residential graduate program. For example, $4 \%$ of students who completed the MicroMasters did not have a bachelor's degree $(\mathrm{N}=20)$. Additionally, $6 \%$ of MicroMasters participants were age 50 or older when they earned the credential $(\mathrm{N}=34)$ and $3 \%$ were under 25 years old $(\mathrm{N}=17)$. By comparison, all of the students in the residential graduate program were under age 50 and all of them already had earned bachelor's degrees.

\section{[Insert Table 1 Here]}

There were several potential filtering mechanisms within the courses that may have resulted in limiting access to certain groups of students. For one, completing the online courses also required a significant time commitment from students. Students who completed the MicroMasters spent an average of 157 hours on the edX platform over 287 days (an average of about 33 minutes a day). This does not include any potential time spent outside the edX platform working on the courses. In our interviews with students in the blended program, one recurring theme was how students juggled their schedules in order to make time for completing the courses. Students scheduled time for course content around their work lives - waking up early, 
working during lunch, or working late into the evening. One student described his experience in the online course this way:

That was very, very tough. I work a lot. I work sometimes I would say 60 hours a week....And I was doing the online courses between 1:00 and 3:00 AM in the morning so that was very tiring and a lot of tea to keep going like that.

Another time factor that may have affected participants' abilities to complete the courses was other caregiving and childcare responsibilities, which research has found overwhelmingly affect females (Craig, 2016). In interviews with blended students, female learners with young children described the challenges of successfully completing the online courses. As one participated observed about her experience:

It was hard. It was really hard. So I used to basically wake up early morning before the kids were up, and used to spend that hour in the morning studying. And then the kids used to get into bed at 8:00, so started again stay up late night and study.

Another filtering mechanism was having highly developed self-regulated learning behaviors. Table 2 displays course-level averages by students' level of completion of the program for indicators of self-regulated learning behaviors, which drew from previous research on self-regulated learning in MOOCs (e.g., Kizilcec, Pérez-Sanagustín, et al., 2017). Compared to students who paid the verification fee but did not complete a course, students who completed the MicroMasters spent significantly more time in the course $(\mathrm{W}=18325317, p<0.001)$ and 
were more likely to post in the course forums $(\mathrm{W}=12738280, p<0.001)$. Additionally, they were significantly more likely to revisit previously watched videos $(\mathrm{W}=15212285, p<0.001)$ and answer problems they had previously answered correctly $(\mathrm{W}=12190543, p<0.001)$, perhaps reflecting participants engaging in "retrieval practice" a learning strategy where learners test their knowledge as they process new information (Karpicke \& Roediger, 2008; Kizilcec et al., 2017).

[Insert Table 2 Here]

Self-regulated learning behavior was also associated with learners' demographic characteristics. Male students $(\mathrm{W}=30065468, p<0.001)$ and students with master's degrees $(\mathrm{W}=42123989, p<0.001)$ were significantly more likely to report re-watching previously completed videos (Table 3). To the extent that self-regulated learning habits are fostered and supported through socio-environmental factors, the courses favored students who already had a well-developed repertoire of self-regulated learning strategies through previous learning experiences (Zimmerman, 1989). These differences in self-regulated behaviors may partly explain the demographic gaps between those who completed and those who did not complete the MicroMaster

\section{[Insert Table 3 Here]}

In interviews with blended students, participants described using self-regulated strategies in their learning. For example, one student described an instance of "metacognitive monitoring" (Zimmerman, 2008) where he recognized that his approach to learning wasn't working and decided to switch tactics mid-way through the MicroMasters: 
So I think the first one, SC1x was the first course that I did, and I didn't really do that well. I think I was just trying to figure out how to manage... But I think by the latter part of SC1x, I had my strategy pretty good.....The moment the next material is released, I just print out everything in a booklet format, which I used to keep with me. And in my rides to the office, I used to just skim through it.

In this section, we have described how, on average, males and participants with master's degrees were more likely to complete the sequence of online courses leading to a MicroMasters. Several potential filtering mechanisms existed within the course including the time required to complete the courses and the ability to effectively self-regulate one's learning in an asynchronous online learning environment. These factors may partly explain the demographic imbalance in MicroMasters completion rates.

\subsection{Design Hypothesis 2: Online learning experiences can provide quality professional}

\section{learning at lower costs.}

MicroMasters completers reported that they enrolled in the online courses because they were interested in course content and were looking for ways to advance their careers. Across all entrance surveys, $87 \%$ of students who completed the MicroMasters said "learning about course content" and $83 \%$ said "advancing my career" was a very or extremely important reason for taking the courses. The majority of MicroMasters completers (87\%) were working full-time while they completed the online courses.

Participants described the job-relevant content of the courses as one major factor in drawing them into the courses. Course lectures described high-level concepts and related them to 
practical field applications. Assessments focused on integrating the ideas and concepts from within examples based on real-life supply chain management scenarios. Participants expressed that they found the material engaging and relevant to their current work. One participant described his experience in the course this way:

It's gonna sound geeky but just learning about the analytical aspects of supply chain management really interested me. And just all this knowledge that I kind of knew tangentially from my work in operations but once you start getting into the basics of it, this is why this is the way that is, just all that that I didn't know....And that got just got my juices flowing for the knowledge.

Additionally, several participants described how the courses provided a formal introduction that explained and defined common work experiences. As one student explained, "Sometimes at work there are things that you realize on your own. But then when I was doing the course, it turns out this thing had a name, you know? This was the most appealing thing to me". Of the blended students we interviewed, $84 \%$ said they found that the course helped them in their job performance and many shared examples of how they were able to apply what they learned in their work. For example, one participant described how he made connections between a concept he learned in one of the online courses and something he was doing in his work:

I used all my learning from [the courses], to challenge my supplier back saying that, "You can do this whole production as per the schedule, and this is the planning you should do. Let me know where you feel that you have a challenge. 
In addition to reporting the quality of professional learning, blended students described the lower costs and time commitment as one aspect that they appreciated about the online courses. The original online courses cost $\$ 150$ per course and could be completed in a few months while students were continuing to work full time. As one student described in an interview, "I think it [gives] you more flexible time to work on that. So, to me... it also gives you a very low cost to know the knowledge [to enter] to the industry, so I really like it." Another student also echoed the emphasis on the lower cost to entry "[I thought] 'Okay it's an online course and it's cheap.' I decided to go for it."

Despite the lower cost of the online courses (compared to residential programs), blended students reported that based on what they learned in their online courses they felt highly prepared for their in-person courses. In their end-of-semester surveys, after their residential semester at MIT, $100 \%$ of blended students "agreed" or "strongly agreed" that they felt academically prepared for the courses in their program (Figure 2). In interviews, blended students described the online classes as potentially superior to residential classes. For example, when they were learning technical concepts, they were able to review material immediately. One student made the following observation:

So, some of the concepts that were presented online were a lot more technical and maybe difficult to grasp immediately, especially for some people, being able to rewind, redo it, having the quick feedback from the practice questions, things like that. I think in a more traditional residential classroom setting would be difficult. 
However, blended students also described the residential program as adding value to their online learning experiences. Interviewees particularly appreciated the ability to work on complex problems with other students which they felt would be difficult to replicate in an online environment. One blended student reported the following experience:

I think in online courses, there's always a right answer. And that does not mean it's easier, but it's more structured and it's intended to guide us through to the single answer.

Whereas here, it's a lot more open-ended, which is a lot more interesting, but it requires you to actually think of a lot more complicated stuff.

Overall, blended students felt that the online courses provided quality learning experiences. Blended mentioned the job-embedded content, the flexibility of the courses, the low costs, and the technological affordances of the online courses, such as being able to rewind content, as all adding value to their learning experience.

\subsection{Design Hypothesis 3: Inverted admissions for graduate degree programs can attract high-quality students who otherwise would not attend}

Of the 622 participants who earned a MicroMasters credential by May 2017, 130 applied to MIT's accelerated one-semester blended master's degree program in supply chain management. Admission was a holistic process; students were required to submit letters of recommendation and write essays. However, it differed from the standard admissions process in two key ways: 1) instead of considering GPA, transcripts, and standardized test scores, the 
admissions committee used scores from the online courses and 2) only students who completed the MicroMasters were eligible to apply to the blended program.

This inverted admission process led to several important differences in the blended cohort. First, compared to the residential cohort, blended students were older, had more work experience, and were substantially more likely to already have a master's degree $(57 \%$ for blended students versus $19 \%$ for residential students). Second, most blended students only applied to MIT. Compared with residential students, $71 \%$ of whom reported considering other graduate programs, only $6 \%$ of blended students said they had other considered other graduate degree programs. One student reflected on how the opportunity to come to MIT influenced his thinking about the MicroMasters:

They're looking for the inverted admissions through the MicroMasters to the proper degree program. And then it became like, okay. So this is more a decision point; this looks like this course is turning towards a degree.

Additionally, residential students often planned to use the degree as a career steppingstone, while blended students often planned to remain in their current roles. Seventy-one percent of blended students interviewed said they had the option to go back to their previous position compared to only $13 \%$ of residential students.

A few participants in the blended program did not fit the profile of traditional students in the residential program. One student had worked in humanitarian logistics prior to coming to the program, coordinating relief efforts in war and disaster zones; another student had dropped out of college twenty years earlier and was only now returning to higher education. 
However, by and large, participants in the blended program had similar career pathways as residential students. Most blended (83\%) and residential students (79\%) had previously worked in the supply chain management field. In interviews, residential and blended participants mostly said they planned to pursue management positions within the field. Very few blended participants described the MOOCs as a gateway into supply chain management. Indeed, the most common experience was that they were already working in supply chain management in looking for more formal ways to improve their understanding of the field.

Despite only spending one semester on campus, blended students reported feeling similarly high levels of belonging to the institution. In the end-of-semester survey, blended students reported similar levels compared to residential students, of seeing themselves as part of the larger institutional community and believing they made the right decision to attend the university (Figure 2). For many blended students, the sense of connection to the institution began when they were taking the online classes, even before they formally enrolled in the graduate program. In interviews, one student described feeling like they were part of an existing community when they were still taking the online MicroMasters classes:

The same names pop up. The same names answer questions. We have a LinkedIn group that's kinda separate from the MIT one. We start emailing each other. We have a WhatsApp group as well and things like that. Yeah, when I came here... a lot of the names were already familiar.

Additionally, blended students described interactions with other students during the classes as being an important part of their on-campus learning experiences. In the end-of- 
semester survey, $66 \%$ of blended students said they learned from teamwork in SCM courses and $84 \%$ of students agreed or strongly agreed that other students positively influenced their intellectual growth (Figure 2).

\section{[Insert Figure 2 Here]}

We further explored whether the inverted-admissions program attracted a high-quality cohort of students, by examining differences in course grade between blended, residential, and students outside of the SCM program who took the same courses. Using a linear regression model, we compared the residential course grades received by students in the blended program, to those students in the same classes in the residential or non-SCM programs. On average, Blended students had slightly higher grades in their residential courses than residential students $(\beta=0.11, t=3.26, d f=3,374, p<0.01)$ and students from outside the program who were in the same classes ( $\beta=0.25, t=10.42, d f=3,374, p<0.001)$ (Figure 3 ). As a sensitivity analysis, we also modeled this relationship using a) a linear regression with fixed effects for course effects and b) a cross-classified random effects model which accounts for variation between students and courses and c) observed mean differences in mean GPA. In all cases, the estimated coefficients were similar to those that we found with the original linear regression model (see Table A4 in supplementary materials for estimates from alternative model specifications). This suggests that the program was largely successful in recruiting and preparing highly qualified applicants through the MOOC-based inverted admissions program.

[Insert Figure 3 Here]

\section{Discussion}

As MOOCs increasingly shift toward degree and professional education models (Reich \& Ruipérez-Valiente, 2019), new questions will emerge about who is most likely to benefit from 
these new models of online learning. Will they provide educational opportunities to underserved populations, as research on the first MOOC-based master's degree has suggested (Goodman et al., 2016)? Or will they serve to re-enforce existing disparities by wealth and education levels (Hansen \& Reich, 2015; Littlejohn et al., 2016).

At the beginning of this article, we outlined three design hypothesis that motivated the development of the MOOC-based professional online and blended degree pathways: (1) online and blended models can improve equity in access to educational experiences both through decreasing the price of education and identifying qualified candidates for inverted admissions through online courses, (2) online learning experiences can reduce tuition costs and opportunity costs but still provide high-quality, flexible learning experiences, and (3) performance in online courses can provide an admissions selection mechanism at least as good as standardized tests performance or previous grades.

In our study of the supply chain management MicroMasters and blended master's degree, we found evidence to support the second and third hypotheses. Students described the content of the courses as high-quality and job-relevant and many found that the affordances of online learning helped them understand the content. Students admitted into the blended program reported being academically prepared by the online courses for their in-person learning experiences. Through their learning in the MicroMasters, blended students demonstrated a mastery of course content and self-regulated learning skills. They also developed a sense of community and belonging in the MicroMasters that persisted through the on-campus courses.

This initial case study also suggests that inverted admissions through MOOC-based blended program can be an effective way of recruiting highly-qualified applicants to professional master's programs who may not have attended otherwise. In some ways, blended students did not 
fit the profile of traditional residential in this program: they were older, more likely to already have advanced degrees, and much more likely to plan on returning their previous job. Yet, although they had a slightly different profile than residential students they still performed well academically in their in-person courses. Indeed, blended students had slightly higher, but still statistically significant, grades in their overlapping in-person courses than students in the residential programs.

Additionally, the findings of this study suggest that MOOC-based online and blended degree programs may work best in areas where there are students who are already price- and time-sensitive. Blended students reported that the lower price and shorter time frame were factors in their decision to apply to the blended program. For degree program directors in competitive fields, our findings suggest that MOOC-based blended options can attract students who may not have applied to a traditional residential graduate program.

We did not find evidence for the first hypothesis, that these types of programs could improve educational equity and thus be an on-ramp into a rapidly growing global field. Although the online courses did initially attract a wide audience of learners; the cohort who completed the MicroMasters was mostly male, highly educated and came from OECD countries. Although we did identify some outliers, such as people without an undergraduate degree, the typical MicroMasters completer came from demographic groups which were already over-represented in supply-chain management positions.

Additionally, students who completed the MicroMasters were more likely to use selfregulated learning strategies such as retaking previously completed problems and watching previously watched videos than non-completers. Male learners and students with master's degrees were more also more likely to use some of self-regulated learning strategies, such as 
watching previously watched videos. Without additional supports to enhance equity, online learning may continue to benefit those who already possess a repertoire of well-developed selfregulated learning skills which enable them to be successful in asynchronous, self-directed formats (Littlejohn \& Hood, 2018). Because these attributes are highly correlated with previous exposure to education (Kizilcec et al., 2017) they may end up producing the same inequitable outcomes found in many in-person settings.

Similarly, the cohort that enrolled in the blended master's graduate program was distinguished from the residential cohort more by age and work experience level than by access to education or previous experience in supply chain management. In fact, a much higher percentage of students in the blended program were men, already had a master's degree and many had been working the field for years. As a result, the program did not appear to open new pathways for people from under-represented groups in supply chain management. Other studies of blended programs have also found that the programs tend to have fewer students from underrepresented groups (Leinonen et al., 2019) and benefit already high-achieving students (Asarta \& Schmidt, 2020).

As other scholars have noted, providing access to educational opportunities is not sufficient to increase equity when the underlying systems reinforce systems of inequity (Peurach et al., 2019). Programs that seek to use MOOC-based pathways to diversify higher education may need to explicitly integrate additional supports for students from under-represented groups. These supports might include developing cohort-based tracks specifically for students from under-represented groups that offer additional supports and build a sense of community. Additionally, there may be value in developing fully blended programs that integrate in-person and online learning. For example, Universidad Galileo in Guatemala has developed a hybrid 
residential-MicroMasters program where residential students can receive credit for MicroMasters courses and local teaching staff help recruit students and provide support while students are taking the online courses (Amado-Salvatierra et al., 2018). Combining high-quality online learning with customizable local supports may help students who otherwise might struggle in an online learning environment.

This study also raises some potential equity concerns in using previous performance in an online course as an admissions measure. Admission measures often screen candidates on selection mechanisms that are imperfectly related to educational goals and can result in inequitable outcomes for certain groups (Linn, 1990; Mattern et al., 2017). Switching from admissions tests and undergraduate grades to performance in online MOOCs changes the selection mechanism but does not necessarily make it more equitable. Although this process can produce highly qualified applicants, as our findings demonstrate, the process screens out potential students who might struggle to learn in an online setting. At the same time, online learning skills are not a prerequisite to success in the fields of logistics and operations.

\section{Conclusion}

This case study of a successful launch of a MicroMasters program can offer some guidance to universities considering similar MOOC-based programs. One major reason students reported persisting through the program was that the learning experience was perceived as being immediately relevant in their professional work. Importantly, students perceived the content of the supply chain management courses, which focused on declarative knowledge, industry examples, and analytical approaches, as well-suited to online learning. These types of skills can be adapted to an online setting without a significant loss of rigor or fidelity (Means et al., 2014). 
This study has a number of limitations. Our study describes a single cohort from one MicroMasters program, and our findings may not generalize to all other MOOC-based online and blended programs. While we have survey responses and log data from all types of online participants, we only interviewed students who attended the on-campus master's program. Our qualitative data for this study only describes the online courses from the perspective of a subset of very successful students. In future research, we aim to collect survey and interview data from a wider range of online participants, in particular, students who paid the verification fee but dropped out of online the courses. A better understanding of why these students dropped out of the courses would help course designers in developing customized supports to helping more types of students persist through the online courses.

That said, the findings of the study provide an illustrated example of the limits and affordances of educational technologies in advancing quality, access, and equity in professional education. We demonstrate how one university expanded its reach in the supply chain management field by creating a MOOC-based credential and blended master's degree alongside a traditional residential master's degree. The program attracted some new types of students who would not have otherwise applied to the traditional residential program, but there was little evidence that this new pathway was a promising new on-ramp for professional learning. Technological affordances of MOOCs and other similar educational technologies will likely neither transform professional higher education nor solve its most stubborn challenges, however, these findings suggest that there may be particular niches where they provide a valuable service to those seeking further education. 


\section{Acknowledgements}

We are grateful to the research assistants, Lauren Oh and Elizabeth Weeks, who contributed to this work. This work was supported through funding from the MIT Office of Open Learning in order to provide guidance to the MIT faculty on the efficacy of this program and to inform the field more broadly.

\section{Notes}

${ }^{1}$ As authors, we had no role in the development or facilitation of the program. 


\section{References}

Al-Imarah, A. A., \& Shields, R. (2018). MOOCs, disruptive innovation and the future of higher education: A conceptual analysis. Innovations in Education and Teaching International, 112. https://doi.org/10.1080/14703297.2018.1443828

Alcorn, B., Christensen, G., \& Kapur, D. (2015). Higher Education and MOOCs in India and the Global South. Change: The Magazine of Higher Learning, 47(3), 42-49. https://doi.org/10.1080/00091383.2015.1040710

Amado-Salvatierra, H. R., Rizzardini, R. H., \& Chan, M. M. (2018). Unbundling Higher Education with Internationalization. Experiences from Two Hybrid Postgraduate Degrees Using MOOCs. Proceedings of 2018 Learning With MOOCS, LWMOOCS 2018, 9-12. https://doi.org/10.1109/LWMOOCS.2018.8534684

Anderson, N. (2015, October 7). MIT floats a new online credential: The MicroMaster's. Washington Post. https://www.washingtonpost.com/news/grade-point/wp/2015/10/07/mitfloats-a-new-online-credential-the-micromasters/

Asarta, C. J., \& Schmidt, J. R. (2020). The effects of online and blended experience on outcomes in a blended learning environment. Internet and Higher Education, 44, 100708. https://doi.org/10.1016/j.iheduc.2019.100708

Bartolomé, A., \& Steffens, K. (2015). Are moocs promising learning environments? Comunicar, 22(44), 91-99. https://doi.org/10.3916/C44-2015-10

Boeije, H. R., Duijnstee, M. S. H., Grypdonck, M. H. F., \& Pool, A. (2002). Encountering the downward phase: Biographical work in people with multiple sclerosis living at home. Social Science and Medicine. https://doi.org/10.1016/S0277-9536(01)00238-6

Brint, S. G., \& Karabel, J. (1989). The diverted dream : community colleges and the promise of educational opportunity in America, 1900-1985. Oxford University Press.

Burgess, T. F., Grimshaw, P., Huaccho Huatuco, L., \& Shaw, N. E. (2017). Mapping the operations and supply chain management field: a journal governance perspective. International Journal of Operations \& Production Management, 37(7), 898-926. https://doi.org/10.1108/ijopm-01-2016-0043

Caudill, J. (2017). The Emerging Formalization of MOOC Coursework: Rise of the MicroMasters. In J. P. Johnston (Ed.), EdMedia: World Conference on Educational Media and Technology (Vol. 2017, Issue 1, pp. 1-6). Association for the Advancement of Computing in Education (AACE). https://www.learntechlib.org/noaccess/178296

Chandler, D. L. (2017). MIT's first MicroMasters learners earn credentials | MIT News. MIT News. http://news.mit.edu/2017/first-micromasters-learners-earn-credentials-0620

Chin, T. A., \& Tat, H. H. (2015). Does gender diversity moderate the relationship between supply chain management practice and performance in the electronic manufacturing services industry? International Journal of Logistics Research and Applications, 18(1), 3545. https://doi.org/10.1080/13675567.2014.945399

Christensen, C. (2017). Plenary Session. SalesForce HigherEd Summit.

Clancy, P., \& Goastellec, G. (2007). Exploring access and equity in higher education: Policy and performance in a comparative perspective. Higher Education Quarterly, 61(2), 136-154. https://doi.org/10.1111/j.1468-2273.2007.00343.x

Costley, C. (2013). Evaluation of the current status and knowledge contributions of professional doctorates. In Quality in Higher Education (Vol. 19, Issue 1, pp. 7-27). Routledge . https://doi.org/10.1080/13538322.2013.772465 
Craig, L. (2016). Contemporary Motherhood. In Contemporary Motherhood. https://doi.org/10.4324/9781315573878

De Vries, H., Elliott, M. N., Kanouse, D. E., \& Teleki, S. S. (2008). Using pooled kappa to summarize interrater agreement across many items. Field Methods, 20(3), 272-282. https://doi.org/10.1177/1525822X08317166

DeBoer, J., Ho, A. D., Stump, G. S., \& Breslow, L. (2014). Changing “Course”: Reconceptualizing educational variables for massive open online courses. Educational Researcher, 43(2), 74-84. https://doi.org/10.3102/0013189X14523038

Deming, D. J., Goldin, C., Katz, L. F., \& Yuchtman, N. (2015). Can online learning bend the higher education cost curve? American Economic Review. https://doi.org/10.1257/aer.p20151024

Donavant, B. W. (2009). The New, Modern Practice of Adult Education Online Instruction in a Continuing Professional Education Setting. Adult Education Quarterly, 59, 227-245. https://doi.org/10.1177/0741713609331546

edX. (2018). EdX launches new master's degrees in partership with top-ranked universities. https://www.edx.org/press/edx-launches-new-masters-degrees-in-partnership-with-topranked-universities

Ehrenberg, R. G. (2015). The Arizona State Global Freshman Academy. Change: The Magazine of Higher Learning, 47(6), 14-17. https://doi.org/10.1080/00091383.2015.1089754

Gershenson, S. (2018). Grade Inflation in High Schools (2005 - 2016). www.edexcellence.net.

Glaser, B. G., \& Strauss, A. L. (1967). The Discovery of Grounded Theory. In Aldine de Gruyter, Inc. https://doi.org/10.2307/588533

Goodman, J., Melkers, J., \& Pallais, A. (2016). NBER WORKING PAPER SERIES CAN ONLINE DELIVERY INCREASE ACCESS TO EDUCATION?

http://www.nber.org/papers/w22754

Greene, J. C., \& Caracelli, V. J. (1997). Defining and describing the paradigm issue in mixedmethod evaluation. New Directions for Evaluation, 1997(74), 5-17. https://doi.org/10.1002/ev.1068

Hansen, J. D., \& Reich, J. (2015). Democratizing education? Examining access and usage patterns in massive open online courses. Science (New York, N.Y.), 350(6265), 1245-1248. https://doi.org/10.1126/science.aab3782

Hausmann, L. R. M., Ye, F., Schofield, J. W., \& Woods, R. L. (2009). Sense of Belonging and Persistence in White and African American First-Year Students. Research in Higher Education, 50(7), 649-669. https://doi.org/10.1007/s11162-009-9137-8

Heath, H., \& Cowley, S. (2004). Developing a grounded theory approach: a comparison of Glaser and Strauss. International Journal of Nursing Studies, 41(2), 141-150. https://doi.org/10.1016/S0020-7489(03)00113-5

Hill, P. (2018). Online Program Management: Spring 2018 view of the market landscape -. ELiterate. https://mfeldstein.com/online-program-management-market-landscape-s2018/

Ho, A. D., Chuang, I., Reich, J., Coleman, C., Whitehill, J., Northcutt, C., Williams, J. J., Hansen, J., Lopez, G., Petersen, R., Nesterko, S., Seaton, D., Mullaney, T., \& Waldo, J. (2015). HarvardX and MITx: Two years of open online courses (Issue 10). http://year4.odl.mit.edu/appendix.html

Jones, E. (2013). Practice-based evidence of evidence-based practice: Professional practice portfolios for the assessment of work-based learning. Quality in Higher Education, 19(1), 56-71. https://doi.org/10.1080/13538322.2013.772467 
Joyner, D. (2018). Toward CS1 at Scale: Building and Testing a MOOC-for-Credit Candidate. L@S '18: Proceedings of the Fifth Annual ACM Conference on Learning at Scale. https://doi.org/10.1145/3231644.3231665

Karpicke, J. D., \& Roediger, H. L. (2008). The Critical Importance of Retrieval for Learning. Science, 319(5865), 966-968. https://doi.org/10.1126/science.1152408

Kizilcec, R. F., Pérez-Sanagustín, M., \& Maldonado, J. J. (2017). Self-regulated learning strategies predict learner behavior and goal attainment in Massive Open Online Courses. Computers and Education, 104, 18-33. https://doi.org/10.1016/j.compedu.2016.10.001

Koller, D., Ng, A., Do, C., \& Chen, Z. (2013). Retention and Intention in Massive Open Online Courses : In Depth. Educause Review, 1-8. https://doi.org/10.1145/2339055.2339064

Lederman, D. (2018, November). Online Education Ascends. Inside Higher Ed. https://www.insidehighered.com/digital-learning/article/2018/11/07/new-data-onlineenrollments-grow-and-share-overall-enrollment

Leinonen, J., Ihantola, P., Leinonen, A., Nygren, H., Kurhila, J., Luukkainen, M., \& Hellas, A. (2019). Admitting students through an open online course in programming: A Multi-year Analysis of Study Success. ICER 2019 - Proceedings of the 2019 ACM Conference on International Computing Education Research, 279-287. https://doi.org/10.1145/3291279.3339417

Lim, P. L., Tinio, V., Smith, M., \& Bhowmick, M. K. (2018). 35 Digital Learning for Developing Asian Countries : Achieving equity, quality and efficiency in education. http://www.oapen.org/record/648692

Linn, R. L. (1990). Admissions Testing: Recommended Uses, Validity, Differential Prediction, and Coaching. Applied Measurement in Education. https://doi.org/10.1207/s15324818ame0304_1

Littlejohn, A., Hood, N., Milligan, C., \& Mustain, P. (2016). Learning in MOOCs: Motivations and self-regulated learning in MOOCs. The Internet and Higher Education, 29, 40-48. https://doi.org/10.1016/J.IHEDUC.2015.12.003

Lopez, G., Seaton, D. T., Ang, A., Tingley, D., \& Chuang, I. (2017). Google BigQuery for Education. Proceedings of the Fourth (2017) ACM Conference on Learning@ Scale $L @ S$ '17, 181-184. https://doi.org/10.1145/3051457.3053980

Margaryan, A., Bianco, M., \& Littlejohn, A. (2015). Instructional quality of Massive Open Online Courses (MOOCs). Computers \& Education, 80, 77-83. https://doi.org/10.1016/J.COMPEDU.2014.08.005

Mattern, K., Sanchez, E., \& Ndum, E. (2017). Why Do Achievement Measures Underpredict Female Academic Performance? Educational Measurement: Issues and Practice. https://doi.org/10.1111/emip.12138

Mattes, M. (2017). The Private Side of Public Higher Education. https://vtechworks.lib.vt.edu/bitstream/handle/10919/83628/PrivateSidePublicHEdu.pdf?se quence $=1 \&$ is Allowed $=\mathrm{y}$

Matthews, L., Power, D., Touboulic, A., \& Marques, L. (2016). Building Bridges: Toward Alternative Theory of Sustainable Supply Chain Management. Journal of Supply Chain Management, 52(1), 82-94. https://doi.org/10.1111/jscm.12097

McCrea, B. (2016). Supply Chain Education for The Masses - Supply Chain Management Review. Supply Chain Education for the Masses. http://www.scmr.com/article/the_big_picture_supply_chain_education_for_the_masses/edu cation 
McCrea, B. (2018). Women in supply chain? How far have we come. Modern Materials Handling, 73(10), 26-31.

McKenzie, L. (2018). Is a shakeout coming for online program management companies? Inside Higher Ed. https://www.insidehighered.com/digital-learning/article/2018/06/04/shakeoutcoming-online-program-management-companies

Means, B., Murphy, R., \& Bakia, M. (2014). Learning Online: What research tells us about whether, when and how. Routledge.

Milligan, C., \& Littlejohn, A. (2016). How health professionals regulate their learning in massive open online courses. Internet and Higher Education. https://doi.org/10.1016/j.iheduc.2016.07.005

Mingle, J. (2018). First students arrive on campus to pursue "hybrid" masters degrees. MIT News. http://news.mit.edu/2018/first-students-arrive-campus-hybrid-supply-chainmanagement-masters-degrees-0130

Nix, N., \& Stiffler, D. (2016). Women in Supply Chain Management. Supply Chain Management Review, 44-51. http://www.awesomeleaders.org/wpcontent/uploads/2016/09/SCMR1609_F_WomanInSC_REV-3.pdf

Perna, L. W., Ruby, A., Boruch, R. F., Wang, N., Scull, J., Ahmad, S., \& Evans, C. (2014). Moving Through MOOCs. Educational Researcher, 43(9), 421-432. https://doi.org/10.3102/0013189X14562423

Peurach, D. J., Cohen, D. K., Yurkofsky, M. M., \& Spillane, J. P. (2019). From Mass Schooling to Education Systems: Changing Patterns in the Organization and Management of Instruction. Review of Research in Education, 43(1), 32-67. https://doi.org/10.3102/0091732X18821131

Reeves, T. C., Herrington, J., \& Oliver, R. (2005). Design Research: A Socially Responsible Approach to Instructional Technology Research in Higher Education. In Journal of Computing in Higher Education Spring (Vol. 16, Issue 2). http://www.carnegiefoundation.org/

Reich, J., \& Ruipérez-Valiente, J. A. (2019). The MOOC Pivot. Science, 363(6423), 130-131. https://doi.org/10.1145/3051457.3053980

Roemer, J. E., \& Trannoy, A. (2015). Equality of Opportunity. In Handbook of Income Distribution (Vol. 2, pp. 217-300). Elsevier B.V. https://doi.org/10.1016/B978-0-44459428-0.00005-9

Sackett, P. R., Kuncel, N. R., Beatty, A. S., Rigdon, J. L., Shen, W., \& Kiger, T. B. (2012). The Role of Socioeconomic Status in SAT-Grade Relationships and in College Admissions Decisions. Psychological Science. https://doi.org/10.1177/0956797612438732

Shaw, J. (2019, January). Can MOOCs Predict the Future of Online Education? Havard Magazine. https://harvardmagazine.com/2019/01/mooc

Teddlie, C., \& Tashakkori, A. (2006). A general typology of research designs featuring mixed ethods. Research in the Schools, 13(1), 12-28. https://doi.org/Article

Whitfield, G., \& Farrell, D. (2010). Diversity In Supply Chains: What Really Matters? Journal of Diversity Management (JDM), 5(4). https://doi.org/10.19030/jdm.v5i4.341

Young, J. R. (2018). EdX Quietly Developing 'MicroBachelors' Program |EdSurge News. https://www.edsurge.com/news/2018-01-25-edx-quietly-developing-microbachelorsprogram

Zheng, Q., Chen, L., \& Burgos, D. (2018). Certificate Authentication and Credit System of MOOCs in China. In The Development of MOOCs in China (pp. 261-276). Springer 
Singapore. https://doi.org/10.1007/978-981-10-6586-6_13

Zimmerman, B. J. (1989). A Social Cognitive View of Self-Regulated Academic Learning. Journal of Educational Psychology, 81(3), 329-339. https://doi.org/10.1037/00220663.81.3.329

Zimmerman, B. J. (2008). Investigating Self-Regulation and Motivation: Historical Background, Methodological Developments, and Future Prospects. American Educational Research Journal. https://doi.org/10.3102/0002831207312909 


\section{Table 1}

Student Demographics by Completion Level and Blended and Residential cohorts

\begin{tabular}{|c|c|c|c|c|c|c|}
\hline & $\begin{array}{c}\text { Mean } \\
\text { Age (SD) }\end{array}$ & $\%$ Female & $\begin{array}{c}\% \text { North } \\
\text { American }\end{array}$ & $\begin{array}{l}\% \text { OECD } \\
\text { Country }\end{array}$ & $\begin{array}{l}\% \text { Master's } \\
\text { Degree }\end{array}$ & $\mathbf{N}$ \\
\hline $\begin{array}{l}\text { Non-verified } \\
\text { students } \\
\text { Did not pay the } \\
\text { verification fee }\end{array}$ & $32.4(9.1)$ & $24 \%$ & $29 \%$ & $46 \%$ & $35 \%$ & 73,001 \\
\hline $\begin{array}{l}\text { Verified, non- } \\
\text { completers } \\
\text { Paid verification fee } \\
\text { but did not } \\
\text { complete any } \\
\text { courses }\end{array}$ & $34.7(9.1)$ & $25 \%$ & $53 \%$ & $68 \%$ & $35 \%$ & 4,195 \\
\hline $\begin{array}{l}\text { Verified, partial } \\
\text { completers } \\
\text { Paid verification fee } \\
\text { and completed at } \\
\text { least one course }\end{array}$ & $33.8(8.5)$ & $22 \%$ & $38 \%$ & $64 \%$ & $45 \%$ & 3,182 \\
\hline $\begin{array}{l}\text { MicroMasters } \\
\text { Earned the } \\
\text { MicroMasters } \\
\text { credential, did not } \\
\text { enroll in the } \\
\text { blended program }\end{array}$ & $35.1(7.9)$ & $13 \%$ & $45 \%$ & $67 \%$ & $51 \%$ & 582 \\
\hline $\begin{array}{l}\text { Blended } \\
\text { Earned } \\
\text { MicroMasters and } \\
\text { enrolled in the one- } \\
\text { semester blended } \\
\text { program at MIT }\end{array}$ & $32.0(5.5)$ & $28 \%$ & $32 \%$ & $45 \%$ & $57 \%$ & 40 \\
\hline $\begin{array}{l}\text { Residential } \\
\text { Enrolled in the full- } \\
\text { year residential } \\
\text { program at MIT }\end{array}$ & $28.9(3.2)$ & $40 \%$ & $40 \%$ & $45 \%$ & $19 \%$ & 42 \\
\hline
\end{tabular}

Note. Categories are exclusive and represent students' maximum level of completion as of May 2017 when the first MicroMasters assessment occurred. We excluded students who participated in one of the online courses after May 2017. These numbers differ from the numbers reported in Figure 1 because the categories in the figure are cumulative rather than exclusive. 
Table 2

Use of Self-Regulated Learning Behaviors Within Each Course by Completion Level

\begin{tabular}{|c|c|c|c|c|c|}
\hline & $\begin{array}{l}\text { Hours in } \\
\text { Course }\end{array}$ & $\begin{array}{c}\text { Number of Forum } \\
\text { Posts }\end{array}$ & $\begin{array}{c}\text { Number of } \\
\text { Videos } \\
\text { Revisited }\end{array}$ & $\begin{array}{c}\text { Number of } \\
\text { Correct } \\
\text { Problems } \\
\text { Revisited }\end{array}$ & $\mathbf{N}$ \\
\hline $\begin{array}{l}\text { Verified, non- } \\
\text { completers } \\
\text { (Reference) }\end{array}$ & 9.25 & 0.80 & 2.12 & 0.87 & 4,195 \\
\hline $\begin{array}{l}\text { Verified, partial } \\
\text { completers }\end{array}$ & $23.5^{\star \star \star}$ & $2.04^{\star \star \star}$ & $6.44^{* * *}$ & $1.20^{* \star *}$ & 3,182 \\
\hline MicroMasters & $31.40^{* * *}$ & $3.56^{* * * *}$ & $15.5^{\star * *}$ & $1.70^{* * *}$ & 582 \\
\hline Blended & $36.40^{* * *}$ & $25.00^{* \star * *}$ & $18.2^{* \star *}$ & $1.88^{* * *}$ & 40 \\
\hline
\end{tabular}

Note. Verified students only. Categories are exclusive and represent students' level of completion as of May 2017. We excluded students who participated in one of the online courses after May 2017. We defined a "revisit" as returning to a video or problem on a different day to differentiate intentional revisiting from other types of behaviors.

$\dagger p<.1^{*} p<.05^{* *} p<.01^{* \star *} p<.001$ 
Table 3

Use of Self-Regulated Learning Behaviors Within Each Course by Demographics

\begin{tabular}{lccccc}
\hline & $\begin{array}{c}\text { Hours in } \\
\text { Course }\end{array}$ & $\begin{array}{c}\text { Number of } \\
\text { Forum } \\
\text { Posts }\end{array}$ & $\begin{array}{c}\text { Number of } \\
\text { Videos } \\
\text { Revisited }\end{array}$ & $\begin{array}{c}\text { Number of } \\
\text { Correct } \\
\text { Problems } \\
\text { Revisited }\end{array}$ & N \\
\hline Female & 20.59 & 1.71 & 5.74 & 1.17 & 1,723 \\
Male & 20.14 & 2.29 & $6.75^{* * *}$ & 1.27 & 5.867 \\
\hline No Master's & 19.81 & 2.29 & 6.29 & 1.19 & 4,503 \\
Masters' & $20.96^{* * *}$ & 2.10 & $7.06^{* * *}$ & 1.18 & 3,646 \\
\hline Non-OECD & $20.65 \dagger$ & 2.06 & 6.27 & 1.22 & 2,701 \\
OECD & 19.93 & $2.19^{* *}$ & 6.83 & 1.16 & 5,927 \\
\hline Outside North America & $20.61^{* * *}$ & 1.86 & 6.37 & 1.15 & 4,211 \\
North America & 19.72 & $2.56 \dagger$ & $7.06 \dagger$ & 1.21 & 3,646 \\
\hline
\end{tabular}

Note. Verified students only. Categories are exclusive and represent students' level of completion as of May 2017. We excluded students who participated in one of the online courses after May 2017. We defined a "revisit" as returning to a video or problem on a different day to differentiate intentional revisiting from other types of behaviors.

$+p<.1^{*} p<.05^{* *} p<.01{ }^{* * *} p<.001$ 


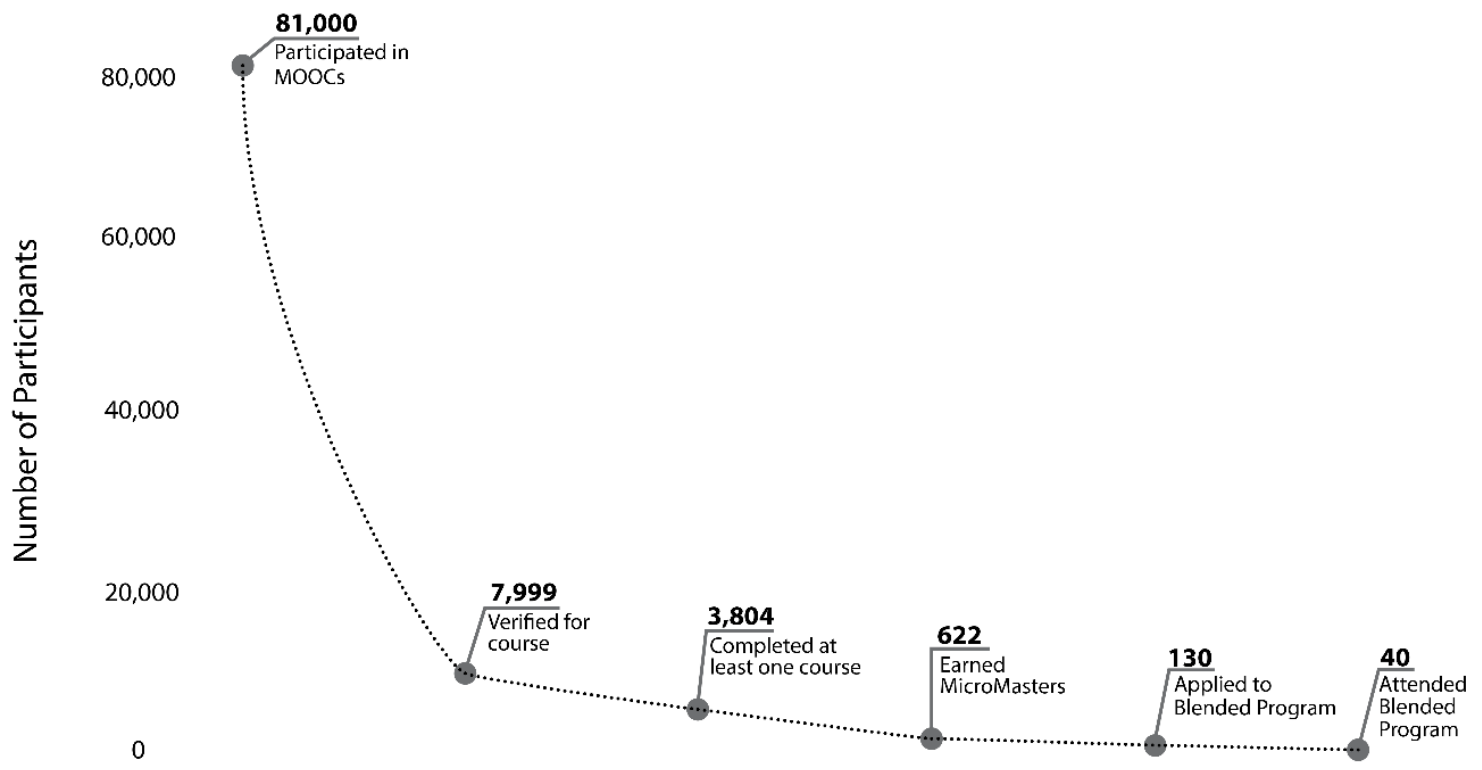

Fig 1. Funnel of participation within the MIT supply chain MicroMasters program.

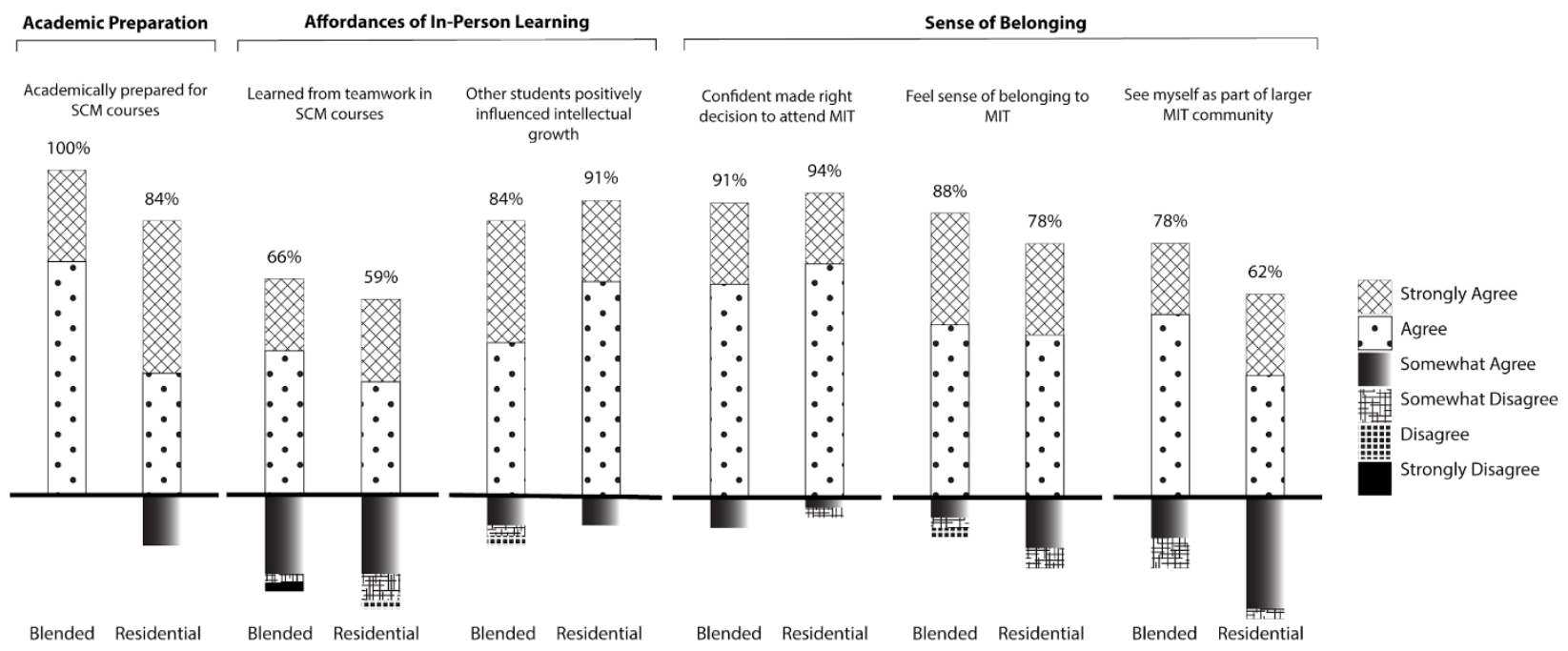

Fig 2. On-campus learning experience by cohort. 
Non-SCM student

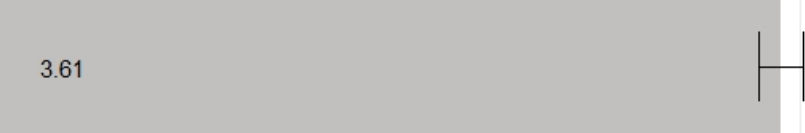

Residential

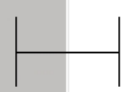

Blended
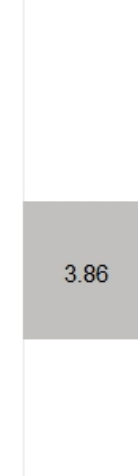

3

3.25

$\stackrel{3.5}{\text { Average student grades }}$

4

Fig 3. Difference in January and spring semester grades by cohort. 